\title{
Efeitos da formação inicial de professores em Tecnologia Assistiva através de metodologia problematizadora
}

\author{
Effects of initial teacher's training on Assistive Technology through problem- \\ solving methodology
}
Efectos de la formación inicial de profesores en Tecnología Asistiva a través de metodología problematizadora

\section{Carolina Rizzotto Schirmer}

Professora doutora na Universidade do Estado do Rio de Janeiro, Rio de Janeiro, Rio de Janeiro, Brasil. ead.carolina@gmail.com

ORCID - http://orcid.org/0000-0002-3668-0269

Leila Regina d'Oliveira de Paula Nunes

Professora doutora na Universidade do Estado do Rio de Janeiro, Rio de Janeiro, Rio de Janeiro, Brasil. leilareginanunes@gmail.com

ORCID - http://orcid.org/0000-0003-2012-6973

Recebido em 23 de janeiro de 2019

Aprovado em 15 de outubro de 2020

Publicado em 25 de novembro de 2020

\section{RESUMO}

O estudo teve como objetivos planejar, implementar e avaliar os efeitos de um programa de formação inicial de professores para atuar com recursos de Tecnologia Assistiva (TA) e de Comunicação Alternativa (CA) nas concepções sobre deficiência desses futuros professores e em sua atuação educacional junto a alunos com deficiência e Transtorno do Espectro Autista (TEA). Uma pesquisa-ação foi conduzida com 37 alunos da graduação do curso de Pedagogia, 26 alunos com deficiência sem fala articulada, e cinco professoras de uma escola especial da rede pública de ensino. Os procedimentos metodológicos envolveram: a) aplicação de questionário aos graduandos no início e ao final do programa; b) oferta de aulas expositivas e desenvolvimento de atividades de ensino pelos graduandos junto aos alunos com deficiência e TEA, de acordo com a Metodologia da Problematização - observação da realidade, seleção de problema pedagógico, reflexão sobre os determinantes do aluno, elaboração de hipóteses, pesquisa bibliográfica, elaboração, implementação e avaliação de plano de ensino. Os dados mostraram efeitos positivos nas concepções dos graduandos em relação aos conceitos de deficiência, TA e CA, e atendimento educacional bem-sucedido, com emprego de muitos recursos e estratégias de $\mathrm{CA}$, material pedagógico adaptado e recursos de acesso ao computador. O estudo beneficiou, ainda, os professores da escola especial, que passaram a conhecer tais recursos, e os alunos com deficiência, que ampliaram as oportunidades de comunicação e interação social.

Palavras-chave: Formação inicial de professores; Tecnologia assistiva; Metodologia da problematização. 
http://dx.doi.org/10.5902/1984686X36505

\section{ABSTRACT}

The purposes of this study were to plan, implement and evaluate a Pre-service Teacher Training Program regarding the use of Assistive Technology and Augmentative and Alternative Communication. The effects of the program in the future teachers' conceptions about disability, as well as their experience in teaching students with special needs were also investigated. An action research was conducted with 37 Pedagogy undergraduate students, 26 nonvocal students, and five teachers of a special education public school. The methodological procedures included a) questionnaires administered to the undergraduates in the beginning and the end of the Program, b) expositive classes and development of teaching activities by the undergraduates, specially tailored for students with special needs, according to the Problematization methodology - observation of the reality of classroom, selection of pedagogical problem, reflection about its determinants, hypothesis elaboration, review of the literature, elaboration, implementation, and evaluation of the teaching plan. Data showed that, following the Program, the future teachers successfully used Alternative Communication resources and strategies, as well as adapted pedagogical material and resources for accessing computer with their nonvocal students. Results additionally suggested positive changes in the undergraduates' conceptions about disability, Assistive Technology and Augmentative and Alternative Communication. The study benefitted special school teachers, who learned about these resources, as well as the nonvocal students who enhanced their opportunities to communicate and socially interact.

Keywords: Teacher training; Assistive technology; Problematization methodology.

\section{RESUMEN}

El estudio tuvo como objetivo planear, implementar y validar los efectos de un programa de formación inicial de profesores para actuar con los recursos de Tecnologia Asistiva (TA) y de Comunicación Alternativa y Aumentativa (CAA) en las concepciones sobre la deficiencia en los futuros profesores en su desempeño educacional junto a los alumnos con deficiencia y Transtorno do Espectro Autista (TEA). Una investigación-acción fue llevada a cabo con 37 alumnos en los cursos finales de Pedagogia, 26 alumnos con deficiencia del habla, y 5 profesores de una escuela especial de la red pública de enseñanza. La metodología consistió en: a) aplicación del cuestionario a los alumnos de Pedagogia al inicio y final del programa; b) oferta de clases expositivas y desarrollo de actividades de enseñanza junto con los alumnos con deficiencia y TEA, de acuerdo con la Metodologia da Problematizacao - observación de la realidade, selección de problema pedagogico, reflexión sobre los determinantes del alumno, elaboración de hipótesis, investigación bibliográfica, elaboración, implementación y validación del plan de enseñanza. Los datos muestran una modificación positiva de las concepciones de los alumnos próximos a graduarse en relación a los conceptos de deficiencia, TA y CAA, y atendimiento educacional suceso, a través de varios recursos y estratégia de CAA, material pedagógico adaptado y recursos de acceso a computadoras. El estudio benefició también, a los profesores de la escuela especializada, que fueron expuestos a tales recursos, y los alumnos con deficiencia que ampliaron sus oportunidades de comunicación e interacción social.

Palabras clave: Formación inicial de profesores; Tecnología asistiva; Metodología de problematización. 
http://dx.doi.org/10.5902/1984686X36505

\section{Introdução}

A formação de professores na perspectiva da Educação Inclusiva envolve o desenvolvimento não só de conhecimentos ligados à Educação Especial, mas também competências profissionais que venham a possibilitar o acolhimento do aluno com deficiência e Transtorno do Espectro Autista (TEA) não apenas para socializá-lo, mas para garantir educação acadêmica de qualidade. Para tanto, é importante que se possa assegurar não só a formação continuada de professores na área, mas também a inicial, que ocorre nos cursos de Pedagogia e Licenciaturas. E que nestas, sejam discutidos, de maneira especifica, a teoria, a pesquisa e a prática na educação especial, com o objetivo de que estes docentes tenham conhecimentos mínimos sobre a área e também habilidades para lidar com a diversidade na sala de aula comum (GREGUOL et al., 2013). Na graduação é necessário que os discentes percebam que, com a heterogeneidade de sujeitos que compõem o espaço escolar na atualidade, há necessidade de que a prática pedagógica, desde o ato de avaliar e planejar, se configure em ação flexível, reflexiva, de modo a atender aos diferentes níveis, ritmos, interesses e motivações dos discentes (MESQUITA, 2009).

A inclusão escolar e social de pessoas com deficiência e TEA assim como as áreas de Tecnologia Assistiva (TA $)^{1}$ e Comunicação Alternativa $(C A)^{2}$ têm sido pensadas e discutidas na literatura brasileira especializada tanto em uma perspectiva clínica como educacional (DELIBERATO, 2007; PELOSI, 2008; PELOSI; NUNES, 2008; 2009; BERSCH, 2009; GALVÃO FILHO; MIRANDA, 2011; LOURENÇO, 2012; ROCHA; DELIBERATO, 2012; GALVÃO FILHO, 2012; GIROTO et al., 2012; SEABRA et al., 2018). Quando falamos de formação de recursos humanos para atuar com TA precisamos pensar não só na capacitação do professor especializado como também dos profissionais da educação em geral bem como das áreas da saúde que são apoio fundamental no processo de inclusão desse aluno com deficiência e TEA. Porém, ainda hoje, são poucas as instituições de ensino superior que oferecem em seus currículos disciplinas, obrigatórias e/ou eletivas, específicas que discutam temas relacionados à Educação Especial, e menos ainda, à área de TA e CA (SCHIRMER et al., 2011). Outro aspecto que cabe destacar é que, muitas vezes, as disciplinas têm caráter meramente informativo, organizadas de maneira tradicional, privilegiando a teoria desvinculada da prática (BUENO; MARIN, 2009).

A literatura cientifica é pródiga em evidenciar que professores, de maneira geral, não estão preparados para receber em sala de aula alunos com deficiência e TEA, reafirmando a necessidade da melhoria da formação de professores como condição indispensável para 
http://dx.doi.org/10.5902/1984686X36505

a inclusão dos alunos no ensino regular (FERREIRA, 2004; GLAT; PLETSCH, 2004; PELOSI, 2008; PLETSCH, 2009; CORRÊA NETTO, 2012; SOUZA, 2015). Com efeito, são numerosos os entraves no processo de inclusão desses sujeitos que, muitas vezes, estão em sala de aula, porém alheios ao processo de aprendizagem, porque não apresentam fala ou escrita funcional, como é o caso daqueles com paralisia cerebral e TEA. Eles são inseridos no ambiente escolar apenas com o propósito de promover a socialização, mas não lhes é dada a oportunidade de aprender, interagir e se comunicar com os outros colegas e com o próprio professor.

Sabemos que são muitas as preocupações que os professores, em geral, apresentam desde a sua graduação, e a qualidade do atendimento educacional aos alunos com necessidades educacionais especiais (NEE) é uma dessas inquietações. Com a crescente presença desses alunos, e, em particular sujeitos com severas dificuldades motoras ou com severos transtornos de comportamento, que se mostram incapazes de se comunicar oralmente nas salas de aula, a proposta da Educação Inclusiva enfrenta um grande impasse. Assim, se concebemos a escola como locus por excelência para a apropriação, pelo aluno, dos elementos e processos culturais e não apenas como ambiente de socialização, importantes transformações se fazem necessárias para que de fato ela se caracterize como inclusiva (NUNES, 2009; SCHIRMER et al., 2011). A literatura sobre a educação desse alunado tem destacado mudanças em pelo menos dois aspectos: 0 emprego planejado e consistente da TA, e nos casos citados anteriormente, mais especificamente, os recursos e serviços da CA e a formação do professor (AUTOR 2, 2008, 2009; CORRÊA NETTO, 2012; SOUZA, 2015; GIROTO et al., 2012; SEABRA et al., 2018).

O objetivo deste trabalho é apresentar uma pesquisa desenvolvida em uma universidade pública do Rio de Janeiro, que teve como objetivo planejar, implementar e avaliar os efeitos da oferta de um programa de formação inicial em Tecnologia Assistiva e Comunicação Alternativa $^{3}$ para alunos da Pedagogia, por meio da abordagem problematizadora.

\section{Proposta de formação inicial e CA}

A relação entre a educação e as novas tecnologias, embora bastante discutida, continua sendo para os professores e as escolas um grande desafio, ainda mais quando relacionados à Educação Especial (PELOSI; NUNES, 2009). Por isso, torna-se necessário que os futuros professores em sua formação também tenham acesso ao conhecimento 
http://dx.doi.org/10.5902/1984686X36505

teórico-prático voltado ao uso dessas ferramentas. Compreendemos que a formação inicial não deve consistir apenas no repasse de um saber fora de sala de aula, mas também na possibilidade de rever a escola/prática educativa, e analisar as potencialidades de uma intervenção colaborativa sistemática entre futuros e atuais professores de alunos com deficiências na comunicação. Além do domínio de recursos tecnológicos da CA como pranchas e cartões de comunicação, sistemas computadorizados e softwares especiais, é essencial a presença de interlocutores interessados em interagir e comunicar com esse alunado e oferecer-lhe melhor qualidade de vida, favorecendo seu protagonismo, autonomia e consequentemente sua inclusão escolar e social.

As Instituições de Ensino Superior (IES) têm sido estimuladas a prover um ensino que, dentre outros atributos, valorize a qualidade da educação para todos e que estimule nos professores habilidades como as de resolução de problemas e colaboração. Vários autores reportam a necessidade de se romper com o modelo tradicional de formação e discutem o processo educacional no mundo contemporâneo. Eles são eloquentes em ressaltar a importância da mudança da postura do professor, o qual é considerado o responsável pela transmissão de informações, cabendo aos alunos o papel de indivíduos passivos, preocupados apenas em recuperar tais informações quando solicitados (CANDAU, 2007; FREIRE, 1975; VENTURELLI, 1997; CYRINO; TORALLES-PEREIRA, 2004). Esses autores descrevem ainda experiências inovadoras em uma disciplina ou entre disciplinas de um mesmo curso, que podem contribuir para a melhoria da qualidade do processo ensino- aprendizagem nas instituições. A proposta é relacionar o conteúdo das disciplinas a conhecimentos prévios dos alunos, bem como aos seus interesses, exigindo deles a capacidade de atribuir significado próprio aos conteúdos que assimilam, e requisitando aos professores tarefas que favoreçam esta aprendizagem (CUNHA et al., 2001; CYRINO; TORALLES-PEREIRA, 2004).

Por isso a abordagem educacional escolhida e que será descrita no decorrer deste artigo está baseada nos pressupostos da Metodologia da Problematização (MP), que estimula o aprender a aprender (BERBEL, 1998) e consequentemente a metacognição do estudante, ou seja, as habilidades de auto monitoramento de seu processo de aprendizagem. A metacognição é elemento essencial da aprendizagem bem-sucedida e envolve o estabelecimento do objetivo da ação, a seleção das estratégias e a avaliação dos resultados por parte do aprendiz. A MP tem como ponto de partida e chegada um estudo, por exemplo de um caso, um recorte da realidade concreta, sendo esta observada sob 
http://dx.doi.org/10.5902/1984686X36505

diversos ângulos, o que permite ao discente ou pesquisador extrair e identificar os problemas ali existentes (CORTES et al., 2018).

\section{Método}

\section{Participantes}

Participaram do estudo 37 alunos regularmente matriculados em duas disciplinas do curso de Pedagogia de uma universidade pública do Rio de Janeiro. As disciplinas em questão foram as de Pesquisa e Práticas Pedagógicas II e Pesquisa e Práticas Pedagógicas IV4. Também participaram do estudo uma terapeuta ocupacional, duas psicólogas e duas fonoaudiólogas que faziam parte de um grupo de pesquisa da universidade, as duas professoras responsáveis pela disciplina Pesquisa e Prática Pedagógicas, 26 alunos com deficiência, com idades entre 8 e 32 anos, cinco professoras de uma escola especial da rede pública de ensino do município do Rio de Janeiro.

\section{Local}

O estudo ocorreu em dois lugares: na Faculdade de Educação — em salas de aula e em um espaço destinado a pesquisa, ensino e extensão na área de Tecnologia Assistiva e Comunicação Alternativa - e em uma escola especial da rede pública de ensino.

\section{Instrumentos}

Os seguintes instrumentos foram utilizados: questionário de coleta de dados e autoavaliação (respondidos pelos graduandos); recursos de TA (produzidos pelos graduandos); diário de campo (que continha as impressões e anotações da pesquisadora); vídeos e fotografias (produzidos pelos graduandos e pela pesquisadora).

Foram empregados ainda nos atendimentos, recursos de TA, filmadoras e audiogravadores digitais, assim como computadores/notebooks, plastificadora e impressoras. Os recursos de alta e baixa TA envolveram três modalidades bastante utilizadas no contexto escolar: Auxílios para a Vida Diária - AVDs (material pedagógico, escolar e lúdico adaptado ou especialmente desenvolvido), Informática Acessível (teclados e mouses especiais, acionadores e outros) e CA (pranchas e cartões de comunicação, vocalizadores e sistemas de comunicação computadorizados, softwares de CA). 
http://dx.doi.org/10.5902/1984686X36505

\section{Procedimentos gerais}

O projeto foi submetido à apreciação da Direção da Faculdade de Educação e da Direção da Secretaria Municipal de Educação (SME), que o aprovaram. Após o aceite das direções, o projeto foi submetido e aprovado pela Comissão de Ética em Pesquisa Parecer Coep no 008.3.2009.

Para a realização do survey, que visava a caracterização dos graduandos do curso de Pedagogia de uma universidade pública e de suas concepções acerca da deficiência, deficiência física, TA e CA, foi elaborado um questionário pela pesquisadora e por parte da equipe interdisciplinar do Grupo de Pesquisa. As questões foram adaptadas do instrumento validado por Pelosi (2008). Após a elaboração, o questionário foi aplicado a uma turma de 23 graduandos de Pedagogia matriculados na disciplina Questões Atuais em Educação Especial para ser avaliado quanto à clareza e à coerência. Os alunos responderam e fizeram críticas e sugestões, as quais serviram de base para a sua reformulação. Os graduandos das disciplinas Pesquisa e Prática Pedagógica II e Pesquisa e Prática Pedagógica IV foram então convidados a participar da pesquisa no primeiro dia de aula do segundo semestre de 2008. Após a apresentação do projeto e da equipe interdisciplinar aos alunos, aqueles que aceitaram participar assinaram o Termo de Consentimento Livre e Esclarecido (TCLE). Foi aplicado então como pré-teste, o questionário em pauta que continha 21 questões fechadas e semiabertas, para identificação e caracterização dos participantes, e 12 questões semiabertas e abertas sobre conhecimentos dos alunos sobre deficiência, TA e CA. Ao término do curso, os participantes responderam ao questionário novamente (pós-teste), com o objetivo de avaliar o conhecimento adquirido no curso, rever seus conteúdos e traçar os objetivos de trabalho para a continuação da formação.

No primeiro semestre os graduandos participaram de um curso teórico-prático de 60 horas sobre TA, com ênfase em CA de acordo com as demandas levantadas no questionário inicial. Ao final do semestre, em dezembro de 2008, o curso foi avaliado pelos alunos e pela pesquisadora. Com base nesses dados, foi verificado que era preciso modificar a metodologia aplicada, de forma a valorizar a necessidade dos graduandos de experienciar atividades práticas e empregar os recursos de TA e CA junto a pessoas com deficiência e TEA. Esses dados nortearam a proposta da continuação do curso de formação inicial com base nos pressupostos da metodologia da Problematização. 
http://dx.doi.org/10.5902/1984686X36505

\section{Procedimentos específicos}

A observação, o planejamento e o desenvolvimento de proposta de intervenção direta junto alunos com deficiência e TEA ocorreram em salas de aula e no espaço destinado a pesquisa, ensino e extensão na área de Tecnologia Assistiva e Comunicação Alternativa da Faculdade de Educação, onde tais alunos, encaminhados pelo centro de referência da Educação Especial da SME, receberam atendimento especializado de CA e TA ofertado pelos graduandos de Pedagogia.

Os graduandos foram divididos em pequenos grupos e encaminhados a cinco turmas de uma escola especial ou ao espaço de TA dentro da Faculdade de Educação, para observar e interagir junto aos alunos com NEE, suas professoras e familiares.

Os semestres foram divididos em quatro etapas, descritas a seguir:

- Primeira Etapa. Solicitou-se a cada pequeno grupo que escolhesse um aluno com NEE ou uma turma, e procurasse identificar, junto à professora regente, o familiar e/ou a pesquisadora, um problema relevante no ensino desse aluno ou dessa turma. Após a observação (três sessões de observação), era organizado um encontro com a supervisora. Nesse encontro, os graduandos apresentavam o caso-problema. Eles descreviam um problema que julgassem pertinente no ensino do aluno ou da turma. A supervisora/pesquisadora recomendava leituras para estudo e aprofundamento.

- Segunda Etapa. Após o aprofundamento teórico, o grupo de graduandos deveria levantar hipóteses para a resolução do problema selecionado e buscar referencial teórico que o levasse a estabelecer objetivos da ação pedagógica (três encontros). Seguia-se uma nova supervisão.

- Terceira Etapa. Cada grupo então deveria selecionar as estratégias de atuação e os materiais didáticos e tecnológicos necessários (três encontros). Nova supervisão para discussão e avaliação do processo era então realizada.

Quarta Etapa. Em seguida, cada grupo deveria implementar o plano de intervenção educacional especializado, avaliar os resultados e propor nova ação e continuação do processo (três encontros). Nessa etapa, que correspondeu ao final do semestre, todos os grupos apresentaram os trabalhos de forma oral, e entregaram o estudo de caso por escrito. Os recursos elaborados pelos alunos de graduação, após serem avaliados por eles, pela 
http://dx.doi.org/10.5902/1984686X36505

pesquisadora e pelas professoras da disciplina, foram entregues aos alunos com deficiência e TEA. Nos casos nos quais o graduando realizou trabalho com uma turma e o produto final - recurso pedagógico - tivesse sido desenvolvido para ela, como um livro ou um jogo adaptado, este era entregue para a professora regente.

Esse processo ocorreu no período de março de 2009 a dezembro de 2010 (durante quatro semestres da graduação), totalizando 240 horas de formação inicial.

Os objetivos gerais da formação foram: iniciar a preparação dos graduandos para atuarem com alunos com deficiência e TEA, sem fala articulada funcional; desenvolver a habilidade de relatar observações do aluno com deficiência, por meio de estudo de caso; utilizar o estudo de caso para a elaboração do plano de intervenção especializada, que possibilitasse o desenvolvimento de estratégias adequadas ao desenvolvimento do aluno tanto no atendimento especializado quanto na escola. A formação objetivou também: estimular parcerias entre o aluno da graduação, o aluno com deficiência, a família, os profissionais da escola e da saúde (quando era o caso) na construção do planejamento e na resolução dos problemas que pudessem surgir na escolarização do aluno com deficiência. Desenvolver no aluno de graduação as habilidades de auto monitoramento ${ }^{5}$ de seu processo de aprendizagem foi igualmente buscado.

\section{Análise dos dados}

No estudo foram realizadas análises quantitativas das questões fechadas e análise de conteúdo das questões descritivas. A técnica utilizada foi a de análise categorial (que consiste em uma análise de conteúdo), que funciona por operações de desmembramento do texto em categorias, segundo reagrupamentos analógicos (BARDIN, 1997). Os dados coletados nas perguntas fechadas dos estudos foram organizados em banco de dados, usando-se os softwares Microsoft Office Access e Excel. O primeiro, auxiliando a organização dos dados em categorias, para facilitar a análise, e o segundo, auxiliando a quantificação dos resultados e possibilitando a criação de gráficos ilustrativos. A regra de enumeração considerada nas análises quantitativas foi a frequência de aparição de cada categoria de resposta. Nas análises qualitativas a inferência foi fundamentada na presença do tema ou palavra e não sobre a frequência de sua aparição. No decorrer do texto, os tópicos que foram analisados quantitativamente aparecem com seu valor percentual entre parênteses. 
http://dx.doi.org/10.5902/1984686X36505

A análise de conteúdo foi realizada em duas etapas: a) no final do 1ํsemestre (análise das respostas coletadas nos questionários iniciais); b) após a oferta dos quatro semestres de formação, com abordagem Problematizadora (análise dos questionários do pós teste, dos trabalhos desenvolvidos no curso e do diário de campo).

De posse dos dados, coube à pesquisadora encaminhar a análise a partir de uma categorização de temas, o que possibilitou uma organização mais clara das informações obtidas. Neste caso, as respostas dos participantes foram classificadas em duas categorias: Perfil dos graduandos e Metodologia Problematizadora e Intervenção Educacional Especializada.

\section{Resultados e Discussão}

\section{Perfil dos graduandos}

Os resultados sobre o conhecimento dos graduandos de Pedagogia, colhidos através dos questionários, estão expressos de forma sintética a seguir. Responderam ao questionário inicial, no final do $1^{\circ}$ semestre de formação (1 semestre de 2009), $31^{6}$ alunos, e no final do terceiro semestre ( ${ }^{\circ}$ semestre de 2010 ) de formação, $26^{7}$ alunos regularmente matriculados na disciplina Pesquisa e Prática Pedagógica.

Em síntese os graduandos de Pedagogia, em sua maioria do sexo feminino, ao iniciarem a formação, tinham idade entre 18 e 20 anos, e cursavam entre o terceiro e o quinto período. Vinte e dois alunos (55\%) afirmaram que ainda não tinham assistido aulas de disciplina dentro da temática Educação Especial/Inclusiva. Muitos dos que já haviam participado dessas aulas afirmaram que "as disciplinas eram muito teóricas e que esperavam que nessa pesquisa/curso eles tivessem a possibilidade de viver a prática, que até o momento estava somente no papel".

Poker et al. (2017) desenvolveram uma pesquisa que teve por objetivo identificar as percepções sobre a formação inicial recebida pelos egressos do curso de Pedagogia da Faculdade de Filosofia e Ciências - UNESP/Marília (Brasil) e também verificar se esta promoveu uma formação em direção à perspectiva educacional inclusiva. Um dos aspectos citados foi a necessidade de práticas. Com efeito, os egressos destacaram que seria importante haver estágio curricular na área da educação especial/inclusiva para o graduando conhecer e compreender as particularidades desse aluno no contexto da educação inclusiva. Barbosa-Vioto e Vitaliano (2013) também desenvolveram um estudo 
http://dx.doi.org/10.5902/1984686X36505

semelhante que objetivou identificar, junto aos egressos do curso de Pedagogia de uma universidade pública brasileira as suas percepções sobre a formação inicial recebida para promover educação inclusiva e um dos resultados apontados foi a necessidade de inserção de oportunidades de estágio em educação inclusiva para aprimorar a formação. Esses dados foram importantes para a escolha da metodologia utilizada em nossa formação.

Quase a totalidade dos sujeitos deste estudo não havia participado de qualquer curso na área de CA e TA. Apenas vinte e cinco alunos (63\%) tinham conhecimento e convivência com alguma pessoa com deficiência, porém as experiências foram consideradas como: “"superficiais", "com pouco aprofundamento". Em relação às concepções, foram percebidas modificações significativas em grande parte dos discentes ao final do estudo. Se antes do curso, $45 \%$ dos alunos conceituavam deficiência como um sinônimo de incapacidade, após o curso apenas 13,5\% mantinham a mesma concepção. O fato de quase metade do grupo de participantes não possuir contato mais significativo ou vivência com pessoas com deficiência explicaria respostas nas quais enfatizam a necessidade da prática, porque a prática garantiria o contato ou a vivência da área.

No estudo desenvolvido por Poker et al. (2017) os egressos consideraram "importante" a presença das cinco disciplinas que trataram da educação especial ao longo de sua formação, porém consideraram que o curso apenas parcialmente para a atuação junto aos alunos com NEE e que por não terem tido a experiência do estágio "sentem-se inseguros" para agir frente a esse alunado.

No presente estudo, ao verificar que quase $98 \%$ dos alunos de graduação se mostraram disponíveis e interessados em trabalhar diretamente com pessoas com deficiência e exibiam grande expectativa com relação ao curso proposto, consideramos a urgência em repensar a metodologia a ser utilizada. Parece que encontramos nesta categoria analisada o primeiro ponto-chave para a organização de nossa formação: a valorização da prática reflexiva.

A percepção do trabalho do professor na educação especial/inclusiva também sofreu modificação. Enquanto no pré-teste, este trabalho foi considerado por $53 \%$ dos alunos como "um trabalho difícil”, "muito difícil”, "exige esforço", "árduo", "precisa de boa dose de paciência", "precisa de persistência", no pós-teste apenas 8\% dos participantes continuavam a considerá-lo como um trabalho difícil. Contudo, até mesmo esses alunos já conseguiam refletir sobre as dificuldades, modificando o sentido do termo e relacionandoo com "prazer", "desafio", vislumbrando "inúmeras possibilidades” e justificando que "a 
http://dx.doi.org/10.5902/1984686X36505

dificuldade encontrada se dá pelo fato desse trabalho ser diferente, porém após o contato com o aluno com deficiência não sentimos mais medo, angústia".

Faria e Camargo (2018) realizaram uma revisão sistemática nas publicações nacionais indexadas na base SciELO sobre as emoções do professor frente ao processo da educação inclusiva. As autoras destacaram que os estudos encontrados revelam que a falta de formação específica e o despreparo do professor têm sido frequentemente apontados como fatores que dificultam a inclusão escolar e que "as(os) emoções/afetos/sentimentos mais mencionadas(os), foram: impotência, insegurança, medo, angústia". Em contrapartida, alguns estudos verificaram emoções/ afetos/sentimentos associadas(os) a um relacionamento professor-aluno mais próximo e afetivo, como aceitação, afeto, amor, carinho, sensibilidade e tranquilidade. Os estudos realizados em escolas e que usaram abordagem colaborativa desencadearam as(os) emoções/afetos/sentimentos de comprometimento, liberdade, pertencimento e progresso, além do sentimento de estar atingindo o objetivo de realizar a inclusão escolar.

No presente estudo, a comparação dos questionários realizados antes (pré-teste) e após a oferta do curso (pós-teste), em sua grande maioria, mostrou mudanças positivas, evidenciando que o curso atingiu os objetivos propostos. Antes, 30 (75\%) alunos referiam não saber o que é Tecnologia Assistiva, e quase $50 \%$ também não sabiam o que é a Comunicação Alternativa. Após o curso, todos os 37 (100\%) alunos mostraram-se conhecedores dessas áreas de conhecimento, reconhecendo sua importância para a pessoa com deficiência, destacando sua aplicabilidade na área educacional e reconhecendo sua necessidade para a inclusão da pessoa com deficiência.

\section{Metodologia Problematizadora e Intervenção Educacional Especializada.}

No primeiro dia de aula, do 10 semestre, foram organizados 14 grupos, com uma média de três graduandos em cada. Essa organização estava prevista, pois, dentro da abordagem utilizada, valoriza-se o trabalho colaborativo com os demais alunos do grupo, assessorado pelo professor e desenvolvido nos contextos reais em que ele irá trabalhar futuramente (CYRINO; TORALLES-PEREIRA, 2004). Pensou-se em grupos com no máximo três alunos para favorecer a troca de conhecimento e o envolvimento de todos.

A proposta da Metodologia da Problematização prevê que os futuros professores encarem as situações-problema em um cenário real (BERBEL, 1998). Para este estudo, os cenários foram a escola e um espaço para atendimento educacional especializado dentro 
http://dx.doi.org/10.5902/1984686X36505

da universidade. Sendo assim, envolveu primeiramente a aceitação da direção da escola, dos professores da escola especial, dos alunos com deficiência e de seus familiares.

Nos estudos de caso apresentados ao final de cada semestre, observou-se o amadurecimento da turma, que aprendeu a descrever o caso resumidamente (tipos de problemas identificados, potencialidades, dificuldades e interesses). Poker et al. (2017) afirmam que o trabalho colaborativo em equipe e o estudo de caso deveriam ser colocados como prioridades a fim de que o professor troque com os demais colegas experiências e saberes e ainda atualize continuamente suas competências.

Nos primeiros resumos de casos lidos, os alunos davam muita importância para informações clínicas, como diagnósticos, por exemplo, ignorando ou desmerecendo informações educacionais. Da mesma forma, no referencial dos estudos de caso, a ênfase era dada também aos autores que falavam dos quadros clínicos (causas e sintomas de paralisia cerebral, deficiência intelectual, deficiência múltipla, transtorno do espectro autista). Provavelmente isso ocorreu porque a Educação Especial se constituiu originalmente como campo de saber e área de atuação, a partir de um modelo médico/clínico (GLAT; ANTUNES, 2012). A cientificidade adotada nas décadas de 1960 e 1970, que estabeleceu o modelo médico e instituiu um diagnóstico-padrão classificatório à pessoa com distúrbios psicomotores e de aprendizagem, ainda predomina em nossa cultura (GLAT, 1995). Portanto, mesmo nas áreas educacional e psicopedagógica, essa visão médica de diagnóstico era e parece ser ainda hegemônica. Essa questão foi discutida com os graduandos ao longo da formação.

Verificou-se que nos semestres seguintes, os dados educacionais foram sendo gradativamente mais enfatizados na descrição do caso e no referencial teórico; os pontos elencados para o estudo passaram a ter relação mais direta com temas como a Educação Especial, Educação Inclusiva, TA e CA. Alguns exemplos de pontos estudados pelos alunos foram: Educação Especial; Educação Inclusiva; Legislação; CA (conceito, recursos, estratégias e escola); adaptação de material pedagógico e escolar; recursos de TA aplicados na escola; avaliação adaptada; o papel da escola; linguagem, comunicação e interação; entre outros. Os títulos dos trabalhos finais também refletiram a mudança: "A importância da Comunicação Alternativa: contribuições e perspectivas da prática pedagógica”, "Avaliação e Comunicação Alternativa e Ampliada na Alfabetização: relato de caso" e "Uso de Tecnologia Assistiva aliada ao Método Narrativo para aluna com deficiência múltipla". 
http://dx.doi.org/10.5902/1984686X36505

Outro elemento que merece destaque foi a oportunidade que os graduandos tiveram de observar como os professores, cuidadores e o próprio sujeito/aluno atuavam no espaço educacional real. Na Problematização, o trabalho colaborativo realizado pelos alunos, organizados em grupos, assessorados pela pesquisadora, e desenvolvido nos contextos reais onde eles irão trabalhar futuramente também afetou a aprendizagem individual na medida em que eles foram expostos a diferentes perspectivas dos problemas em pauta, tiveram oportunidade de observar como os profissionais analisavam os problemas e receberam feedback da pesquisadora, dos alunos, das professoras e das cuidadoras sobre suas próprias ações e sugestões nesse processo (GIJSELAERS, 1996; BROWN; KING, 2000). A maioria dos alunos nunca havia estado em uma escola ou tivera contato com alunos com deficiência. Com essa experiência e com o feedback que receberam, os graduandos puderam rever sua postura não somente perante este alunado, mas também diante de várias outras situações como o comportamento profissional na escola e dentro da sala de aula.

Darius e Stange Lopes (2017) afirmam que as Metodologias Ativas, como a MP, possibilitam aos futuros professores uma articulação entre a universidade, a escola e a comunidade, com o propósito de adquirirem seus conhecimentos por meio de uma leitura e intervenção consistente do cotidiano escolar, permitindo que eles possam relacionar teorias e práticas, promovendo o processo de pensar por meio de um trabalho em equipe.

Essa primeira etapa de conhecimento do aluno e dos problemas teve lugar no período de três encontros, na maioria dos grupos. Com essas informações em mãos, os grupos discutiram com o professor da universidade a solução do problema identificado e relacionaram os principais tópicos para a sua resolução. Para essa etapa foi necessário que eles buscassem referencial teórico e outras bases de informação. A maioria dos graduandos identificou como problemas a comunicação e a interação. Ao longo dos outros semestres da formação, os graduandos que conseguiram estabelecer comunicação e interação efetivas com seus alunos com deficiência passaram a identificar como problema para o aprendizado a não adaptação do material pedagógico ofertado pelas professoras da escola. Alguns grupos estabeleceram relações importantes sobre a acessibilidade arquitetônica, materiais e equipamentos utilizados pelo aluno com deficiência e os recursos disponíveis no ambiente escolar: 
http://dx.doi.org/10.5902/1984686X36505

[...] foi observado que a escola especial é bem-adaptada nas questões arquitetônicas. Porém, com relação à comunicação dos alunos, foram percebidas certas dificuldades, barreiras, até porque nem todos os alunos assim como nem todos os professores, em suas atividades - fazem uso de recursos que auxiliem na comunicação, como pranchas, pastas, cartões, ou seja, recursos de Comunicação Alternativa [...]. (Trecho extraído do trabalho final do 1 을 semestre do grupo 2 )

Todos os graduandos conseguiram chegar à etapa de intervenção com os alunos especiais. A presença e sua atuação na escola foram bem-avaliadas não só pelas professoras como também pelos alunos da escola que ficaram satisfeitos com o trabalho.

[...] a professora Clara $^{8}$ me contou que a aluna Mariana havia estado na escola pela manhã para aplicar a atividade com a turma [...]. Disse que a atividade tinha ficado ótima e que os alunos dela haviam gostado muito. Que foi bem interessante, porque tudo o que ela havia falado para as graduandas sobre o comportamento dos alunos havia acontecido na prática. (Trecho extraído do diário de campo da pesquisadora em 7/7/2009, turno manhã)

Nos trabalhos escritos, os graduandos também expressaram seus sentimentos quanto à atuação, ao desejo de dar continuidade ao trabalho no próximo semestre e à frustração em relação ao pouco tempo disponível:

[...] no começo nos assustamos um pouco, pois nunca tínhamos tido contato direto com pessoas com deficiência, entretanto, depois, acabamos nos acostumando e nos envolvendo com os meninos, com isso deixamos de "ver" as deficiências e começamos a pensar como poderíamos ajudá-los. A cada dia que ficamos lá, passamos por experiências únicas [...]. Além disso, crescemos e derrubamos barreiras internas, como medos e preconceitos. Podemos dizer que não é fácil tirar a teoria do papel, mas que a prática é muito mais prazerosa do que a teoria [...] O incrível é que não importava o quanto havíamos estudado, era tudo novo, aplicar tudo o que a gente aprendeu era um grande desafio. É importante também ressaltar que não importa o comprometimento do aluno, ele também pode ser beneficiado pelo trabalho escolar, com o uso dos recursos da CA [...] (Trecho extraído do trabalho final do 1 을 semestre do grupo 9)

Os graduandos foram convidados a refletir e avaliar seu processo de aprendizagem nos finais dos semestres através do questionário. Essa avaliação trouxe informações importantes para a decisão de manter a metodologia nos demais semestres dos anos letivos de 2009 e 2010, como pode ser constatado no depoimento transcrito a seguir:

[...] eu aprendi como ser um ser humano melhor, de não criar preconceitos sobre alguém e de não criar limitações pra pessoas que possuem deficiências. Aprendi que os deficientes têm suas dificuldades, mas não existem impossibilidades; o problema é que temos tendência a julgar o que não conhecemos, por falta de conhecimento e informação. (Aluna Letícia, final do $1^{\circ}$ semestre de 2009) 
http://dx.doi.org/10.5902/1984686X36505

A abordagem educacional utilizada ofereceu mais autonomia e protagonismo aos alunos de Pedagogia, e os dados sugeriram que eles não estavam habituados com isso. Como consequência, muitas vezes enfrentamos problemas como faltas e atrasos dos graduandos, pouco envolvimento de alguns deles no trabalho e até mesmo dificuldade de compreensão da proposta, que fugia ao padrão das disciplinas que conheciam. A Metodologia da Problematização é, também, uma das manifestações do construtivismo na Educação, e por isso estimula atividades construtivas, quando favorece a aquisição das habilidades de aprender a aprender (CYRINO; TORALLES-PEREIRA, 2004).

A maioria dos graduandos de Pedagogia, no ano de 2009, elencou como principal problema dos alunos com deficiência as dificuldades de comunicação e, consequentemente, de interação. Tiveram a oportunidade de fazer "pequenas" intervenções educacionais, propor um plano de atendimento com objetivos educacionais e foram estimulados a criar recursos e estratégias adequados aos seus alunos.

Vários foram os recursos (pranchas e cartões de comunicação, desenvolvimento de sistema de comunicação de média e alta tecnologia) e atividades (livros, jogos e cadernos adaptados) desenvolvidos pelos graduandos com alunos com deficiência na busca por soluções para os problemas educacionais encontrados. Dessa forma, foram instigados a aprofundar seus conhecimentos na área de TA, para proporem hipóteses de soluções para esses casos e até mesmo implementarem as intervenções. Por fim, a última etapa - a da aplicação à realidade - é aquela que possibilitou aos graduandos intervir nas situações associadas à solução do problema. Para Moraes e Berbel (2006) a aplicação permite fixar as soluções geradas e contempla o comprometimento do pesquisador para voltar para a mesma realidade, transformando-a em algum grau. Essa transformação foi observada nos graduandos em relação à postura (tanto pessoal quanto acadêmica), ao conhecimento e às concepções.

Darius e Stange Lopes (2017) realizaram uma pesquisa que teve como objetivo verificar a percepção dos acadêmicos de Pedagogia de um centro universitário quanto ao desenvolvimento das etapas do Arco de Maguerez $^{9}$, bem como as aprendizagens decorrentes dessa proposta, as vantagens e desvantagens percebidas por eles. A análise dos dados revelou que para $76 \%$ dos alunos, a pesquisa contribuiu para a efetivação do planejamento, visando uma prática transformadora. Os alunos que participaram desse estudo descreveram que a proposta contribuiu para o aprimoramento na realização de uma 
http://dx.doi.org/10.5902/1984686X36505

pesquisa e também no desenvolvimento do pensamento crítico e organização para resolução de problemas.

No presente estudo, muitas foram as dificuldades apresentadas pelos graduandos na organização desse plano de atendimento educacional. A maior dificuldade foi quanto à redação dos objetivos do plano de intervenção, que às vezes não estavam relacionados aos problemas identificados ou eram redigidos em forma de atividades. Os alunos pareciam não ter conhecimento de que um plano de aula sempre começa traçando objetivos e que esses deveriam referir-se às potencialidades e habilidades que 0 aluno poderia desenvolver. Os graduandos também apresentaram, no início, dificuldade para selecionar atividades educacionais que estivessem relacionadas aos objetivos traçados por eles. Apesar das dificuldades, acreditamos que grande parte dos alunos conseguiu perceber a importância do planejamento do professor. Compreender as necessidades e potencialidades do aluno é uma tarefa complexa, mas de fundamental importância para o estabelecimento de programas educacionais que efetivamente contribuam para o seu aprendizado (BUENO, 1999; OMOTE, 2001). O modelo proposto pelo Council for Exceptional Children - CEC (2008) recomenda o desenvolvimento de competência em relação ao planejamento instrucional e com isso propõe que o professor desenvolva habilidades em: elaborar um plano de instrução individualizada geral com objetivos a longo prazo; traduzir esses planos individualizados em objetivos de curto prazo cuidadosamente selecionados onde se leva em consideração as habilidades e necessidades dos indivíduos, e os múltiplos fatores culturais e linguísticos; avaliar continuamente o progresso da aprendizagem do indivíduo. E mais ainda, o professor deve ajudar na facilitação desse plano instrucional num contexto colaborativo, incluindo o aluno com deficiência, sua família, os outros profissionais que atuem com esse aluno especial.

O estudo também possibilitou aos alunos com deficiência e TEA a ampliação das possibilidades de interação e comunicação com outros parceiros (graduandos, professores, cuidadores e colegas, em alguns casos), incrementando, a partir dessa experiência, as suas habilidades tanto linguísticas quanto sociais.

\section{Conclusão}

A Metodologia da Problematização utilizada neste estudo pareceu demonstrar que o contato com o aluno com NEE pode favorecer a internalização do conceito e mudanças nas atitudes e crenças nos graduandos de Pedagogia. Muitos deles no início afirmavam que "a 
pessoa com deficiência é incapaz", porém, ao final do estudo, o discurso e a prática de alguns haviam se modificado. Segundo Berbel $(1998$, p. 36) "trata-se de uma concepção que acredita na educação como uma prática social e não individual ou individualizante".

A opção pela Metodologia da Problematização não demandou muitas alterações materiais ou físicas na escola ou espaço destinado a pesquisa, ensino e extensão na área de Tecnologia Assistiva e Comunicação Alternativa, porém exigiu alterações na postura do professor e dos graduandos, na organização do cronograma, no tratamento reflexivo e crítico dos temas, na flexibilidade de local de estudo e aprendizagem, já que a realidade social é o ponto de partida e de chegada dos estudos pelo grupo de alunos (CYRINO; TORALLES-PEREIRA, 2004).

Enfim, acreditamos que a organização da formação inicial precisa considerar a necessidade e as exigências dos alunos da graduação. É preciso identificar suas concepções, os conceitos que pretendem construir, as metodologias de ensino e os conhecimentos prévios sobre os temas a serem propostos. Por meio da identificação das dificuldades e necessidades e do conhecimento prévio do grupo, será possível planejar um efetivo programa de formação.

\section{Referências}

BARBOSA-VIOTO, J.; VITALIANO, C. R. Educação inclusiva e formação docente: percepção de formandos em pedagogia. Magis: revista internacional de investigación em educacion, v.5, n.11, p. 353-373, 2013.

BARDIN, L. Análise de conteúdo. Tradução de Luís Reto e Augusto Pinheiro. Lisboa: Edições 70, 1997.

BERBEL, N. A. N. A problematização e a aprendizagem baseada em problemas. Interface Comun Saúde Educ; v.2, p. 139-154, 1998.

BERSCH, R. Tecnologia assistiva: metodologia para estruturação de serviço em escolas públicas. 2009. Dissertação (Mestrado em Design) - Programa de Pós-Graduação em Design, Universidade Federal do Rio Grande do Sul, Porto Alegre, 2009.

BROWN, S; KING, F. Constructivist Pedagogy and how we learn: Educational Psychology meets international studies. International Studies Perspectives, v1, p. 245-254, 2000.

\section{BUENO, J. G. S. A educação inclusiva e as novas exigências para a formação de} professores: algumas considerações. In: BICUDO, M.A.; SILVA Jr., C.A. (Orgs.) Formação de educadores e avaliação educacional. São Paulo: UNESP, 1999, p. 146-164. 
http://dx.doi.org/10.5902/1984686X36505

BUENO, J. G. S; MARIN, A. J. Crianças com necessidades educativas especiais, política educacional e a formação de professores: 10 anos depois. In: SEMINÁRIO NACIONAL DE PESQUISA EM EDDUCAÇÃO ESPECIAL: formação de professores em foco, São Paulo, 5., 2009. Anais... São Paulo: ABPEE, 2009.

CANDAU, V. M. F. Formação Continuada de professores: tendências atuais. In: REALI, A.M.M.; MIZUKAMI, M.G.N. (Orgs.). Formação de professores: tendências atuais. São Carlos: EDUFSCar, 2007, p.139-182.

CORREA NETTO, M. M. F. A Comunicação Alternativa e a aprendizagem de crianças com autismo, Asperger e Angelman: formação continuada de profissionais de Educação e Saúde. 2012. 404f. Dissertação (Mestrado em Educação) - Programa de Pós-Graduação em Educação da Universidade do Estado do Rio de Janeiro. Rio de Janeiro, 2012.

CORTES L.F., PADOIN S.M.M., BERBEL N.A.N. Problematization Methodology and Convergent Healthcare Research: praxis proposal in research. Rev Bras Enferm. [Internet]. v.71(2), p.440-445, 2018.

CUNHA, M. I.; MARSICO H.L., BORGES F.A., TAVARES P. Inovações pedagógicas na formação inicial de professores. In: Fernandes C.M.B.; Grillo M. (Org.). Educação superior: travessias e atravessamentos. Canoas: Editora da ULBRA, 2001. p.33-90.

CYRINO, E. G.; TORALLES-PEREIRA, M. L. Trabalhando com estratégias de ensinoaprendizado por descoberta na área da saúde: a problematização e a aprendizagem baseada em problemas. Cad. Saúde Pública, vol.20 no.3. Rio de Janeiro, p.780788, May/June, 2004.

DARIUS, R.P.P.; STANGE LOPES, B. J. O uso da metodologia da problematização para o desenvolvimento de projeto integrador no curso de pedagogia. Revista lbero-

Americana de Estudos em Educação, v. 12, n. 2, p. 983-1004, 2017.

DELIBERATO, D. Comunicação Alternativa: recursos e procedimentos utilizados nos projetos temáticos de classes especiais. In: AUTOR 2; PELOSI, M.; GOMES, M.. (Orgs.). Um retrato da comunicação alternativa no Brasil: relatos de pesquisas e experiências. 1. ed. Rio de Janeiro: Quatro Pontos, 2007. v. 2, p. 61-64.

FARIA, P.M.F.; CAMARGO, D. As Emoções do Professor Frente ao Processo de Inclusão Escolar: uma Revisão Sistemática. Rev. bras. educ. espec., Bauru, v. 24, n. 2, p. 217228, Apr. 2018.

FERREIRA, J. R. Políticas e práticas de educação inclusiva. In: GÓES. Políticas e práticas de educação inclusiva. Campinas: Associados, 2004.

FLAVELL, J. H.; MILLER, P.H., MILLER, S.A. Desenvolvimento cognitivo. Porto Alegre: Artmed; 3. ed., 1999.

FREIRE, P. Pedagogia do oprimido. Rio de Janeiro: Paz e Terra; 1975. 
GALVÃO FILHO, T. A. Tecnologia assistiva: favorecendo o desenvolvimento e a aprendizagem em contextos educacionais inclusivos. In: GIROTO, C. R. M.; POKER, R. B.; OMOTE, S. (Orgs.). As tecnologias nas práticas pedagógicas inclusivas. Marília: Oficina Universitária; São Paulo: Cultura Acadêmica, 2012. p. 65-92.

GALVÃO FILHO, T. A.; MIRANDA, T. G. Tecnologia assistiva e paradigmas educacionais: percepção e prática dos professores. In: Reunião Anual da Associação Nacional de Pós-Graduação e Pesquisa em Educação, 34., 2011, Natal. Anais... Natal: ANPEd, 2011.

GIJSELAERS, W. Connecting problem-based practices with educational theory. New Direction for Teaching and Learning, v.68, p.13-21, 1996.

GIROTO, C. R. M.; POKER, R. B.; OMOTE, S. Educação especial, formação de professores e o uso das tecnologias de informação e comunicação: a construção de práticas pedagógicas inclusivas. In: GIROTO, C. R. M.; POKER, R. B.; OMOTE, S. (Orgs.). As tecnologias nas práticas pedagógicas inclusivas. Marília: Oficina Universitária ; São Paulo: Cultura Acadêmica , 2012. p. 11-24.

GLAT, R. Integração dos portadores de deficiência: uma questão psicossocial. Revista Temas em Psicologia, n. 2, p. 88-94, 1995.

GLAT, R.; PLETSCH, M. D. O papel da universidade frente às políticas públicas para Educação Inclusiva. Revista Benjamim Constant, Rio de Janeiro ano 10, n. 29, p. 3-8, 2004.

GLAT, R.; ANTUNES, K. C. V. Pesquisa em educação especial: reflexões sobre sujeitos, ética e metodologia. In: TAQUETTE, S. R.; CALDAS, C. P. (Org.). Ética e pesquisa com populações vulneráveis. Rio de Janeiro: Eduerj, 2012, p. 267-292.

GREGUOL, M.; GOBBI, E.; CARRARO, A. Formação de professores para a educação especial: uma discussão sobre os modelos brasileiro e italiano. Rev. bras. educ. espec., Marília, v. 19, n. 3, p. 307-324, Sept. 2013.

LOURENÇO, G. F. Avaliação de um programa de formação sobre recursos de Alta Tecnologia Assistiva e Escolarização. 2012. Tese (Doutorado em Educação Especial) -Programa de Pós-Graduação em Educação Especial, Universidade Federal de São Carlos, São Carlos, 2012.

MESQUITA, A.M.A. Discutindo A Formação Inicial de Professores no Contexto da Inclusão. Londrina, 2009.

MORAES, K. C.; BERBEL, N. A. O uso da metodologia da problematização para a investigação sobre avaliação da aprendizagem. O que há de específico para o ensino superior? Semina: Ciências Sociais e Humanas, Londrina, v. 27, n.2, p. 169-186, jul./dez. 2006. 
NUNES, L. R. O. P. Acessibilidade comunicativa para alunos com deficiência: formação inicial e continuada de professores. Projeto de pesquisa financiado pela FAPERJ (proc. E 26/111794/2008), 2008.

NUNES, L. R. O. P. Dando a voz através de imagens: comunicação alternativa para indivíduos com deficiência. Relatório de pesquisa aprovado pela FAPERJ (proc. E 26/110235/2007), 2009.

OMOTE, S. A concepção de deficiência e a formação do profissional em educação especial. In: MARQUEZINE, M. C.; ALMEIDA, M. A.; TANAKA, E. D. O. (Org). Perspectivas Multidisciplinares em Educação Especial II, Londrina: Ed. UEL, 2001. p.4552.

PELOSI, M. B. Inclusão e Tecnologia Assistiva. 2008. 303 f. Tese (Doutorado em Educação) - Programa de Pós-Graduação em Educação, Universidade do Estado do Rio de Janeiro, Rio de Janeiro, 2008.

PELOSI, M. B.; NUNES, L. R. O. P. Caracterização dos professores itinerantes, suas ações na área de tecnologia assistiva e seu papel como agente de inclusão escolar. Rev. bras. educ. espec., vol.15, p. 141-154, 2009.

PLETSCH, M. Repensando a Inclusão escolar de pessoas com deficiência mental: diretrizes políticas, currículo e práticas pedagógicas. Tese (Doutorado em Educação) Universidade do Estado do Rio de Janeiro, Fundação Carlos Chagas Filho de Amparo a Pesq. do Estado do Rio de Janeiro. 2009.

POKER, R. B.; VALENTIM, F. O. D.; GARLA, I. A. Inclusão escolar e formação inicial de professores: a percepção de alunos egressos de um curso de Pedagogia. Revista Eletrônica de Educação, v.11, n.3, p.876-889, set./dez., 2017.

PRADO, M. L. et al. Arco de Charles Maguerez: refletindo estratégias de metodologia ativa na formação de profissionais de saúde. Esc. Anna Nery, Rio de Janeiro, v. 16, n. 1, p. 172-177, Mar. 2012.

ROCHA, A. N. D. C.; DELIBERATO, D. Tecnologia assistiva para a criança com paralisia cerebral na escola: identificação das necessidades. Revista Brasileira de Educação Especial, Marília: ABPEE, v. 18, n. 1, p. 71- 92, jan./mar. 2012.

SCHIRMER, C.R.; WALTER, C. C. F.; NUNES, L. R. O. P. Formação Inicial de professores: da pesquisa à prática. In: AUTOR 2 et al. (Org.) Comunicar é preciso: em busca das melhores práticas da educação do aluno com deficiência. Marília: ABPEE, 2011, v.1, p. 13-23.

SEABRA JUNIOR, M. O.; LACERDA, L. C. Z. Atendimento Educacional Especializado: planejamento e uso do recurso pedagógico. Rev. Bras. Educ., Rio de Janeiro, v. 23, e230016, 2018. 
http://dx.doi.org/10.5902/1984686X36505

SOUZA, V. L.V. Ações colaborativas em comunicação alternativa para crianças com deficiência no ensino infantil. 2015. 315 f. Tese (Doutorado em Educação) - Programa de Pós-Graduação em Educação, Universidade do Estado do Rio de Janeiro, Rio de Janeiro, 2015.

VENTURELLI, J. Educación médica: nuevos enfoques, metas y métodos. Washington, DC: Organización Panamericana de la Salud/Organización Mundial de la Salud; 1997.

\section{Notas}

${ }^{1}$ Tecnologia Assistiva é uma área do conhecimento que engloba serviços e recursos e se propõe a promover e ampliar habilidades em pessoas com limitações funcionais decorrentes de deficiência e do envelhecimento (PELOSI, 2008; BERSCH, 2009).

2 Comunicação Alternativa é uma das modalidades da TA que atende pessoas sem fala ou escrita funcional ou em defasagem entre sua necessidade comunicativa e sua habilidade em falar e/ou escrever. (PELOSI, 2008; BERSCH, 2009).

${ }^{3} \mathrm{O}$ estudo apresentado foi financiado pela FAPERJ.

${ }^{4}$ As disciplinas Pesquisa e Práticas Pedagógicas são componentes curriculares do curso de Pedagogia. Cabe a essas disciplinas a integração dos diversos componentes curriculares, tanto quanto a consolidação dos campos de formação e a articulação entre a formação teórica e as experiências práticas do estágio curricular.

${ }^{5}$ Como planejar, direcionar e avaliar seu comportamento, alocar estratégias de aprendizagem para resolver problemas e monitorizar seu sucesso ou seu fracasso no desempenho, sendo capaz de decidir sobre o uso de estratégias diferentes e saber do esforço necessário para utilizar essas estratégias (FLAVELL; MILLER; MILLER, 1999).

6 Iniciamos o primeiro semestre de 2009 com 31 alunos, pois alguns 6 alunos não se matricularam nas disciplinas de PPP III e V. Fomos informados que dois alunos mudaram a matricula para o curso noturno por questões profissionais.

${ }^{7}$ Ao final do primeiro semestre de 2009 concluíram os 31 alunos matriculados, porém apenas 26 quiseram responder ao questionário. Terminamos a formação com 23 alunos, pois uma das turmas de PPP, que participaram da pesquisa, haviam concluído a disciplina antes.

8 Todos os nomes utilizados no artigo são fictícios.

${ }^{9} \mathrm{O}$ Arco de Charles Maguerez ou Arco de Maguerez é uma das estratégias de ensino-aprendizagem para o desenvolvimento da Metodologia da Problematização. São as cinco etapas que ocorrem a partir da realidade social: a observação da realidade e definição do problema, os pontos-chaves, a teorização, as hipóteses de solução e aplicação à realidade (PRADO et al., 2012).

\section{Correspondência}

Carolina Rizzotto Schirmer - Universidade do Estado do Rio de Janeiro, Centro de Educação e Humanidades, Rua São Francisco Xavier, n. 532-fim, Rio de Janeiro, RJ - Brasil. CEP: 20550-018.

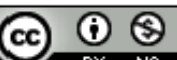
International (CC BY-NC 4.0) 